\title{
An experimental study of a built-middle Photovoltaic Trombe wall system
}

\author{
Yuan Lin ${ }^{\mathrm{a}, \mathrm{b}}$, Jie $\mathrm{Ji}^{\mathrm{a}, *}$, Jinwei Ma ${ }^{\mathrm{b}}$, Xuefei $\mathrm{Li}^{\mathrm{b}}$ \\ ${ }^{a}$ Department of Thermal Science and Energy Engineering, University of Science and Technology of China, Hefei 230026, China \\ b Department of Architectural Environment and Energy Engineering, Anhui Jianzhu University, Hefei 230009, China
}

\begin{abstract}
This paper proposed a PV-integrated Trombe wall system (PVTW) with the photovoltaic panel installed in the middle of air channel, named as built-middle photovoltaic Trombe wall system (PVMTW). The system has multiple functions: such as photovoltaic power generation, passive space heating, heat preservation and heat insulation. A series of tests were carried out in winter between the comparable hotboxes to investigate the thermal and electrical performance of the PVMTW system. The results showed that the average electrical efficiency and thermal efficiency were 0.12 and 0.40 , respectively, under the natural convection mode. The total efficiency of the PVMTW system was calculated to be 0.587 , which is $11.4 \%$ higher than that of traditional PVTW system with the solar cells laminated on the glass cover.
\end{abstract}

\section{Introduction}

PV-Trombe wall (PVTW) has attracted more and more attention because it has multiple functions such as power generation, space heating in winter and heat preservation. The PVTW system can be grouped into three major types according to the installation position of the PV panel in the Trombe wall system from the published literatures. One is that the PV panel was laminated on the surface of glass, also known as built-out photovoltaic integrated Trombe wall (PVOTW) system[1]. The one $\mathrm{Su}$ et al. [2] proposed to attach to the PV panel on the massive wall, also known as built-in photovoltaic integrated Trombe wall (PVITW) system. In addition, $\mathrm{Hu}$ et al. [3] proposed another different design structure of PV blind-integrated Trombe wall (PVBTW) system, for the PVBTW system, the PV blind was used for shading devices as well as electricity generator.

According to the survey, among the various techniques employed to improve the performance of the PVTW system, few people previously have proposed to install the PV panel in the middle of the air channel. Therefore, a new design of the PVTW system is proposed in this paper. The PV panel laminated on the heat absorber plate is installed in the middle of the air channel of the Trombe wall system, which is called as built-middle photovoltaic integrated Trombe wall (PVMTW). The schematic diagram of the PVMTW system is presented in Fig.1. This new PVMTW system has multiple functions: space heating, thermal insulation and electricity generation. The purpose of this paper is to investigate the thermal and electrical performances of the PVMTW system through experimental studies by comparison with the traditional PVOTW system.
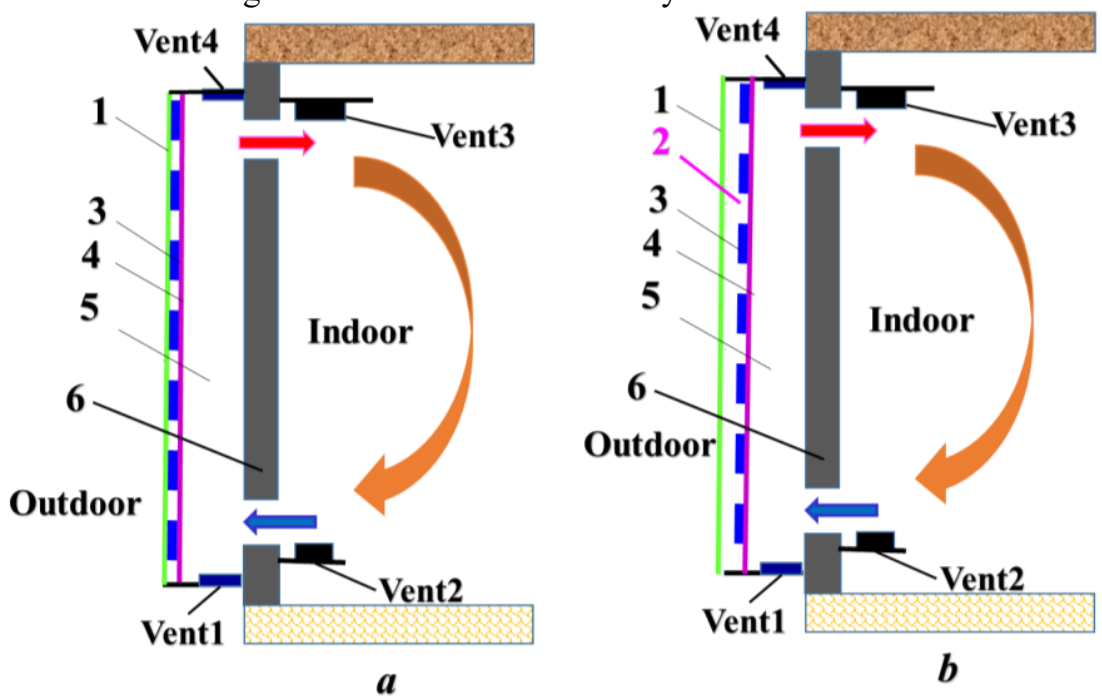

\section{Glass cover}

2. Air layer

3. PV cells

4. Absorber plate

5. Air channel

6. Massive wall

Fig.1 The schematic of Trombe wall with photovoltaic cells (a-the traditional PVOTW system, b-PVMTW system)

\footnotetext{
* Corresponding author. Tel.: 0086-551-63607346. E-mail address: jijie@ustc.edu.cn
} 


\section{Description of the experimental setup}

The experimental rig contains two hotbox buildings with the same dimension of $3900 \mathrm{~mm}$ (depth) $\times 3800 \mathrm{~mm}$ (width) $\times 2600 \mathrm{~mm}$ (height), as shown in Fig.2. Two types of PVTW systems are installed on the south facade walls of two hot box buildings in Hefei $\left(117^{\circ} \mathrm{E}, 32^{\circ} \mathrm{N}\right)$, China. Expect for the south wall, the other orientated wall of the two hot-box are constructed to be the same. Both types of
PVTW systems consist a glass cover with a thickness of $3.2 \mathrm{~mm}$, PV cells, absorber plate, and an air channel with $1700 \mathrm{~mm}$ (height) $\times 900 \mathrm{~mm}$ (width), a 50-mm- thick insulation backplane and a south-facing massive wall, as shown in Fig.1. There are four air vents of the same size of $800 \mathrm{~mm}$ (length) $\times 80 \mathrm{~mm}$ (width) in the each of PVTW system. The PV panel as the power unit consists of 50 pieces mono-crystalline silicon cell of the same size 156 $\mathrm{mm}$ (length) $\times 156 \mathrm{~mm}$ (width) in parallel by a wire, with 0.60 PV cells coverage ratio (Fig.2b).

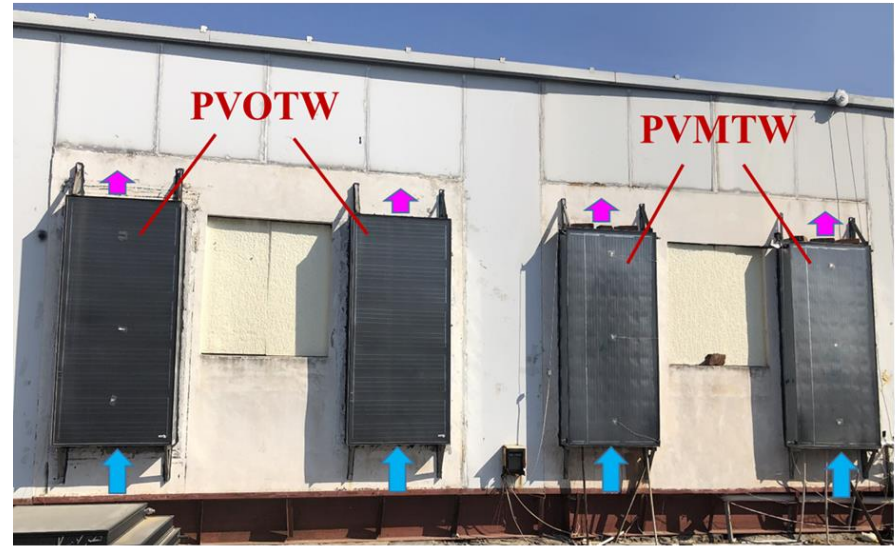

$\boldsymbol{a}$

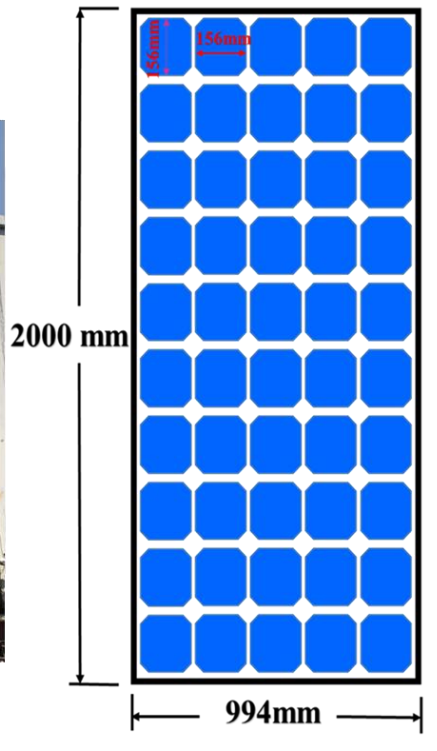

b

Fig.2. Photo of south facade wall of comparative hot boxes with PVTW system and the front view of PV Cells Panel (a-contrast hot box with PVTW system, b- the front view of PV Cells Panel)

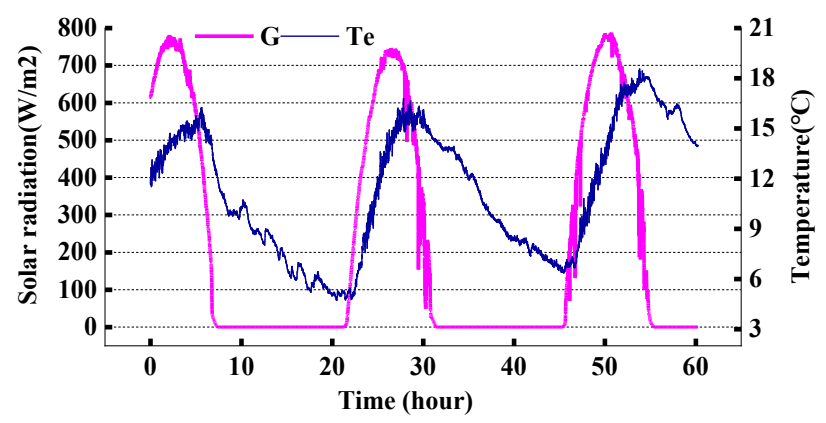

Fig.3. Environmental temperature and vertical solar irradiation

The experiments were carried out from December 20th, 2017 to December 22nd, 2017 (9:00-16:00) and the weather was characterized mostly by sunny conditions during the test period, as shown in Fig.3. Radiation intensity on the vertical surface and temperature of all measuring points are measured by pyranometer and thermocouples, respectively. The power generated by PV cells is charged to the storage battery by the charging controller. All test data will be recorded and saved by a portable data acquisition instrument (Agilent34980A) during the experiment. The time step for the data acquisition instrument is set to be $30 \mathrm{~s}$. During the experiment, the vent 2 and vent 3 are kept open, and the other vents are closed at daytime, while at night all vents are closed to reduce the heat loss.

\section{Performance evaluation of PVTW system}

The instantaneous thermal and electrical efficiency of PVTW system is given by:

$$
\begin{aligned}
& \eta_{e}=\frac{U \cdot I}{G \cdot F_{g} \cdot \zeta} \\
& \eta_{t h}=\frac{Q_{t h}}{G \cdot F_{g}}
\end{aligned}
$$

where the heat gains are given as:

$$
Q_{t h}=u_{a} \cdot F_{c h} \cdot \rho_{a} \cdot c_{a}\left(\mathrm{~T}_{a, \text { upper }}-\mathrm{T}_{a, \text { lower }}\right)
$$

In view of electrical energy is high-grade energy, total $\operatorname{efficiency}\left(\eta_{\text {total }}\right)$ is now introduced to evaluate the combined performance of PVTW systems [4], expressed as:

$$
\eta_{\text {total }}=\eta_{t h}+\zeta \cdot \eta_{e} / \eta_{\text {power }}
$$

where $\eta_{\text {power }}$ is the power generation efficiency of coalfired power plants, and its value is 0.38 .

\section{Results and discussion}

Fig.4 depicts the comparison of heat gains and thermal efficiency between the PVOTW system and the PVMTW 
system. The results show the daily heat gains obtained from the PVMTW system is $11.74 \mathrm{MJ}, 11.57 \mathrm{MJ}$ and 12.43 $\mathrm{MJ}$, while that from the PVOTW system is $8.87 \mathrm{MJ}, 8.30$ $\mathrm{MJ}$, and $9.32 \mathrm{MJ}$ on 20th December, 21st December and 22nd December. It is also found that the instantaneous thermal efficiency of the PVMTW system ranges from 0.28 to 0.48 , and that of PVOTW system ranges from 0.21 to 0.36 during the experiment. According to the
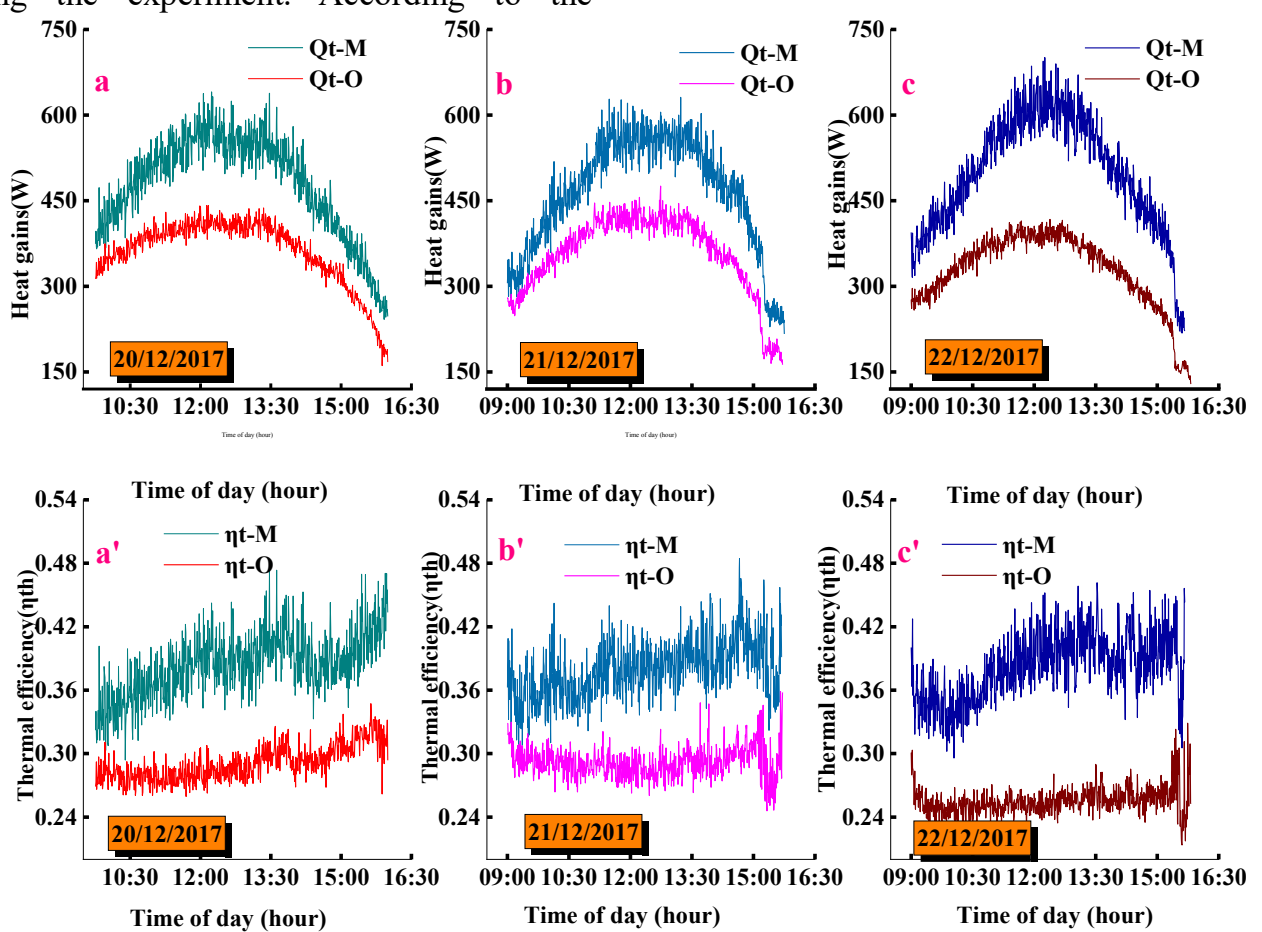

Fig.4. Comparison of heat gains and thermal efficiency between the PVMTW system and PVOTW system $\left(\mathrm{Q}_{\mathrm{t}}\right.$, $\eta_{\mathrm{t}}$-heat gains and thermal efficiency; M-PVMTW system; O-PVOTW system).

Fig.5 shows the changes in power output and the photoelectric conversion efficiency of the two types of PVTW system. According to the data in the Fig.5, the daily output power of the PVMTW system is $0.58 \mathrm{kWh}$, $0.62 \mathrm{kWh}$, and $0.64 \mathrm{kWh}$ during the experiment, and that of the PVOTW system is $0.73 \mathrm{kWh}, 0.74 \mathrm{kWh}$ and 0.77 $\mathrm{kWh}$ respectively. The average photoelectric conversion efficiencies of the two types of PVTW system are 0.12 and calculation, the average thermal efficiency of two kinds of PVTW systems are 0.40 and 0.29 , respectively. The ormer is 1.38 times that of the latter. It is obvious that the the PVMTW system is greater than that reduced by the PVOTW system. therefore, the PVMTW system contributes more to building energy saving.
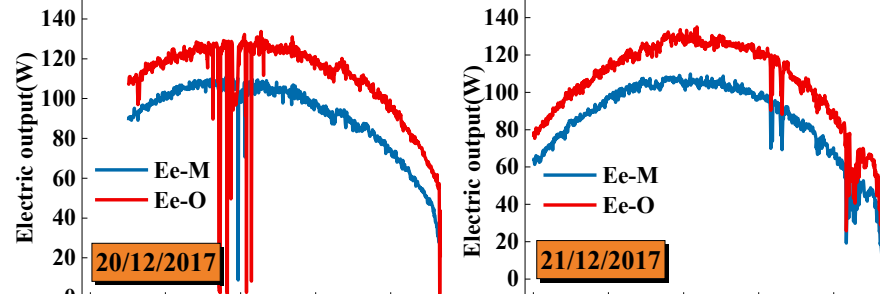

0.15 , respectively. The reason is that the higher temperature of PV cells of the PVMTW system reduces the photoelectric conversion efficiency. The change of temperatures on PV cells for both PVTW systems is shown in Fig.6. Through the temperatures curve in the Fig.6, we can find that the PV cells temperature of the PVMTW system is significantly higher than that of the PVOTW system during the experiment.
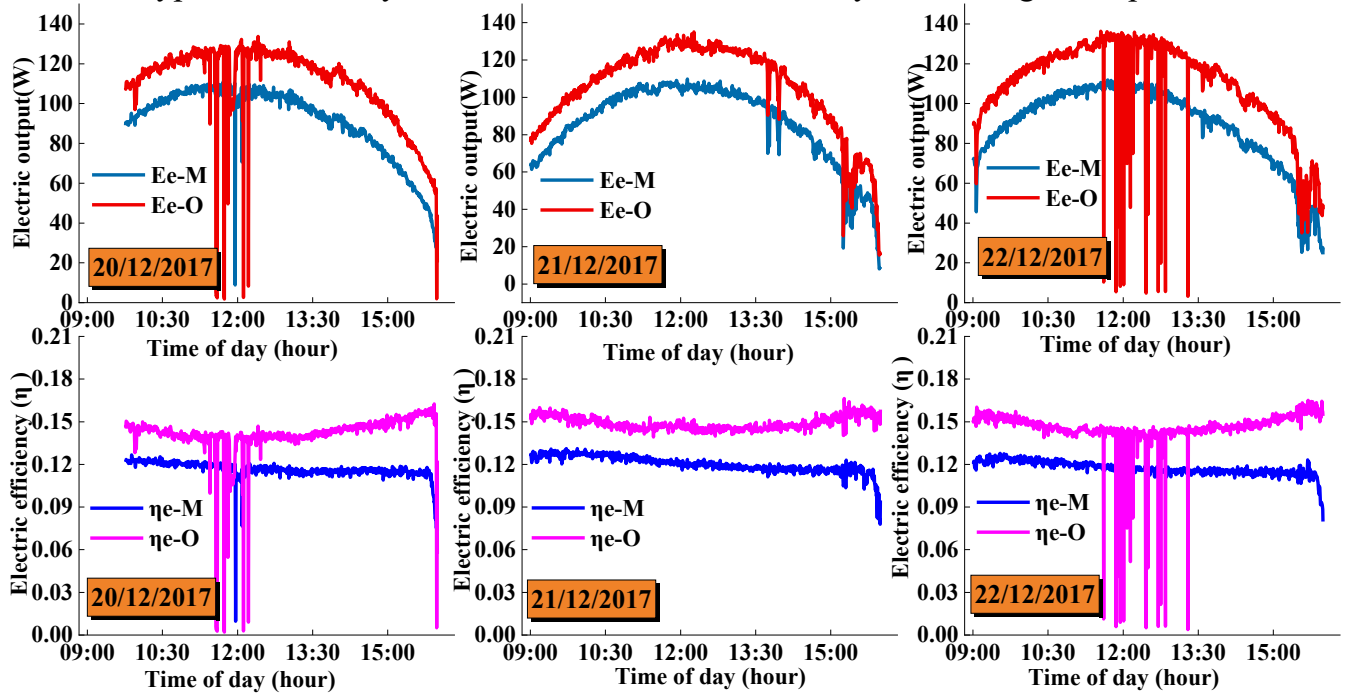

Fig.5. Comparison of electricity output and electrical efficiency between the PVMTW system and the PVOTW system (Eeelectricity output; $\eta_{\mathrm{e}}$ - electrical efficiency; M-PVMTW system; O-PVOTW system). 


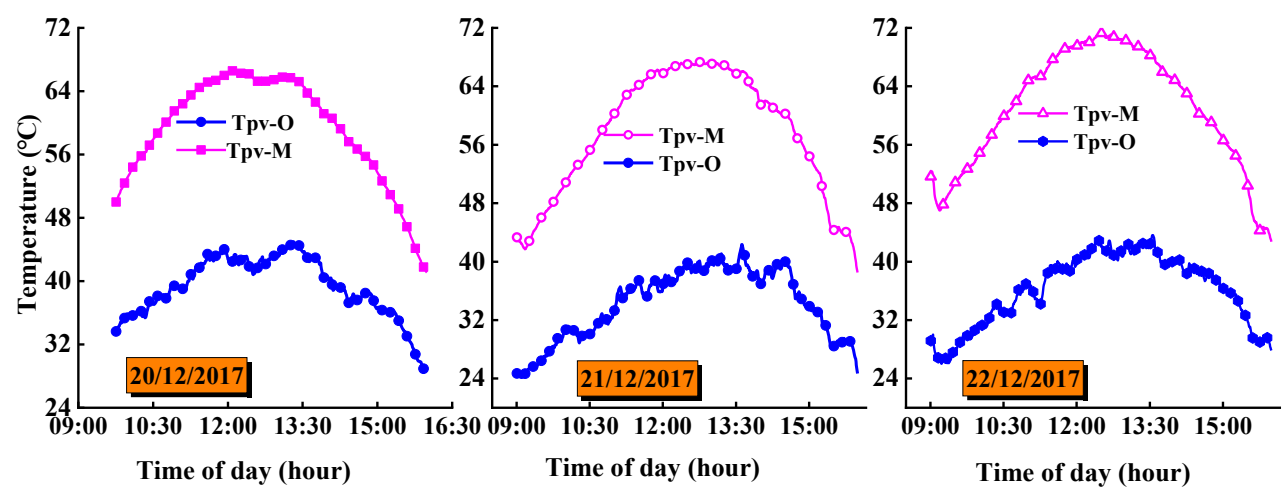

Fig.6. Comparison of the temperature of PV cells (M-PVMTW system; O-PVOTW system)

Table 1 summarizes the comparison results of the two types of PVTW systems. The results show that during the experiment, the average daily total efficiency of PVMTW system is $0.59,0.59$ and 0.58 , while that of PVOTW system are $0.54,0.52$ and 0.52 , respectively. The former

Table 1 Comparisons of the comprehensive performance of two PVTW systems.

\begin{tabular}{ccccccc}
\hline \multirow{2}{*}{ Parameters } & \multicolumn{2}{c}{$20 / 12 / 2017$} & \multicolumn{2}{c}{$21 / 12 / 2017$} & \multicolumn{2}{c}{$22 / 12 / 2017$} \\
& PVMTW & PVOTW & PVMTW & PVOTW & PVMTW & PVOTW \\
\hline thermal efficiency & 0.404 & 0.305 & 0.390 & 0.280 & 0.393 & 0.295 \\
& & & & & & \\
electrical efficiency & 0.118 & 0.150 & 0.122 & 0.150 & 0.119 & 0.145 \\
Total efficiency & 0.59 & 0.54 & 0.59 & 0.52 & 0.58 & 0.52 \\
\hline
\end{tabular}

\section{Conclusions}

In comparison with the traditional PVOTW system, a series of experiments were conducted in winter to investigate the thermal performance, electrical performance and total performance. Some conclusions can be drawn as follows.

(1) The average thermal efficiency of two kinds of average is 0.587 , which is $11.4 \%$ higher than that of the latter. This indicates that the proposed PVMTW system has more advantages in the utilization of solar energy than the conventional PVOTW system.
Nomenclature

G solar radiation intensity, $\mathrm{W} / \mathrm{m}^{2}$

T Temperature, $\mathrm{K}$

c specific heat capacity, $\mathrm{J} /(\mathrm{kg} \cdot \mathrm{K})$

$\mathrm{u} \quad$ speed, $\mathrm{m} / \mathrm{s}$

F area, $\mathrm{m}^{2}$

$Q \quad$ energy, $\mathrm{W}$

$\mathrm{U} \quad$ voltage of PV module, $\mathrm{V}$

I current of PV module, A

$\zeta$ packing factor,-

Abbreviations

PVOTW built-out photovoltaic integrated Trombe wall

PVMTW built-middle photovoltaic integrated Trombe wall

PVITW built-in photovoltaic integrated Trombe wall

PVBTW PV blind-integrated Trombe wall
PVTW systems are 0.40 and 0.29 , respectively. The former is 1.38 times that of the latter.

(2) The results show that the electricity efficiency of the PVMTW system is 0.12 and that of the PVOTW system is 0.15 .

(3) The average of the total efficiency of the PVMTW system is $11.4 \%$ higher than that of the PVOTW system, which indicates that the proposed PVMTW system has more advantages in the utilization of solar energy than the conventional PVOTW system.

Subscripts

g glass

a air

upper upper vent

lower lower vent

th thermal energy

e electricity

ch air channel

power coal-fired thermal power plants total

total 


\section{Acknowledgements}

This research is supported by the National Natural Science Foundation of China (No. 51878636), National Key Technology R\&D Program (No. 2017YFC0702600), Natural Science Foundation of Anhui Province (No.1608085QE108), and Key Laboratory of Huizhou Architecture in Anhui Province.

\section{References}

1. Jie J, Hua Y, Wei H, Gang P, Jianping L, Bin J. Modeling of a novel Trombe wall with PV cells. Building and Environment. 2007;42(3):1544-52.
2. Xu XW, Su YX. Modeling of Natural Ventilation in built-in photovoltaic-Trombe wall. Conference Modeling of Natural Ventilation in built-in photovoltaic-Trombe wall, vol. 448. Trans Tech Publ, p. 1537-41.

3. $\mathrm{Hu} \mathrm{Z,} \mathrm{He} \mathrm{W,} \mathrm{Ji} \mathrm{J,} \mathrm{Hu} \mathrm{D,} \mathrm{Lv} \mathrm{S,} \mathrm{Chen} \mathrm{H,} \mathrm{et} \mathrm{al.}$ Comparative study on the annual performance of three types of building integrated photovoltaic (BIPV) Trombe wall system. Applied energy. 2017; 194:8193.

4. Jiang B, Ji J, Yi H. The influence of PV coverage ratio on thermal and electrical performance of photovoltaic-Trombe wall. Renewable Energy. 2008;33(11):2491-8. 